\title{
"EU DOMMENIQUE": O FEMDOM NO BDSM E SUAS IMPLICAÇÕES PARA AS PERFORMANCES DE GÊNERO E PARA O DISCURSO MÉDICO-RELIGIOSO
}

\author{
Geise Campelo Ferreira*
}

\section{RESUMO}

Este artigo visa discutir subversões dos papéis tradicionais de gênero, encontradas em relações BDSM do tipo FemDom, a partir do livro "Eu, Dommenique", da Dominatrix Profissional Dommenique Luxor. Objetiva-se compreender as dinâmicas subversivas - e também as contradições - que essas relações permitem às mulheres, que ocupam o papel dominante, e aos homens, que ocupam o papel submisso, discutindo algumas práticas que aparecem na narrativa, a saber: Humilhação, Feminização e Inversão. A categoria de análise Gênero será usada para problematizar estas práticas e os papéis socialmente delimitados para homens e mulheres dentro e fora da Comunidade BDSM, considerando a sexualidade expressa nas vivências sadomasoquistas, seus jogos de poder e suas implicações para o discurso heteronormativo-genital construído pela Religião e pela Psiquiatria. Palavras-chave: BDSM; Gênero; Sexualidade; Religião; Psiquiatria.

\section{“EU, DOMMENIQUE": THE FEMDOM IN BDSM AND ITS IMPLICA- TIONS FOR GENDER PERFORMANCES AND FOR MEDICAL-RELIGIOUS DISCOURSE}

\section{ABSTRACT}

This article aims to discuss transgressions of the traditional roles of gender that can be found in BDSM relationships of the FemDom kind, present in the book "Eu Dommenique", from the Professional Dominatrix Dommenique Luxor. The objective is to understand the subversive dynamics - and also their limitations - that these

* Pós-Graduada em Filosofia da Religião na Universidade Metodista de São Paulo (UMESP). Formada em Psicologia pela Universidade Católica de Brasília (2017). Trabalha em Psicologia Clínica com abordagem Fenomenológica-Existencial. Estuda intersecções entre questões de Gênero e Religião, bem como Filosofia Fenomenológica e Existencial. 
relationships allow women, who occupy the dominant role, and men, who occupy the submissive role, discussing some practices that appear in the narrative such as: Humiliation, Feminization and Strapon. The Gender Category of analysis will be used to discuss these practices and the roles socially delimited to men and women inside and outside the BDSM Community, considering the sexuality expressed in the sadomasochists experiences, their power games and the implications to the heteronormative-genital discourse built by Religion and Psychiatry.

Keywords: BDSM; Gender; Sexuality; Religion; Psychiatry.

\section{“EU, DOMMENIQUE": EL FEMDOM EN EL BDSM Y SUS IMPLICACIONES PARA LAS PERFORMANCES DE GÉNERO Y EL DISCURSO MÉDICO-RELIGIOSO}

\section{RESUMEN}

El propósito de este artículo es discutir las subversiones de los roles de género tradicionales que se encuentran en las relaciones BDSM de tipo FemDom, a partir del libro de la Dominatrix Profesional Dommenique Luxor, "Eu, Dommenique". El objetivo es comprender las dinámicas subversivas - y también las contradicciones - que estas relaciones permiten a las mujeres, que ocupan el rol dominante, y a los hombres, que ocupan el rol sumiso, discutiendo algunas prácticas que aparecen en la narrativa, a saber: humillación, feminización e inversión. La categoría de análisis de Género será utilizada para problematizar estas prácticas y los roles socialmente delimitados para hombres y mujeres dentro y fuera de la comunidad BDSM, considerando la sexualidad expresada en experiencias sadomasoquistas, sus juegos de poder y sus implicaciones para el discurso heteronormativo-genital construido por la Religión y la Psiquiatría.

Palabras Clave: BDSM; Género; Sexualidad; Religión; Psiquiatría.

\section{O BDSM E O PANORAMA DA SEXUALIDADE}

A sigla BDSM abrange (porém, não necessariamente resume) uma infinidade de práticas fetichistas que se compreendem dentro de um ou mais princípios do Bondage, Disciplina/Dominação, Submissão/Sadismo e Masoquismo. Nem todas as práticas fetichistas podem encontrar eco dentro do BDSM, mas é comum a associação entre esta comunidade e as mais populares categorias de Fetiche. O acrônimo BDSM e a ade- 
são com sentido erótico das práticas de sadomasoquismo têm estado presentes no Brasil desde meados da década de 80 (Regina FACCHINI; Sarah MACHADO, 2013).

Marcelle Silva (2012) aponta a existência de uma tendência por parte dos indivíduos e das comunidades relacionados ao BDSM em diferenciar um sadomasoquismo criminoso/doentio, relacionados à práticas de tortura com violação de direitos humanos, e o sadomasoquismo erótico que, através das máximas de consensualidade e integridade, a exemplo da base SSC (São, Seguro e Consensual), buscam se distanciar dos estigmas e garantir uma prática prazerosa para os envolvidos. Regina Facchini (2008) aponta, ainda, que a distinção entre o momento da play (jogo/cena) e da realidade baunilha (nome dado às práticas sexuais convencionais/tradicionais socialmente aceitas) é também uma das características do BDSM de cunho erótico.

Essa ressignificação encontra ressonância no trabalho de Maria Gregori, que ao analisar catálogos e manuais sobre SM, identifica definições que contrariam noções de senso comum: "O contradiscurso fornecido acentua, ao contrário, que SM é um exercício erótico de poder e não um abuso físico ou emocional” (Maria GREGORI, 2015, p. 4). Mas no que implica essa preocupação com o SSC, na prática? Vera Silva exemplifica que:

O BDSM define-se como um conjunto de atividades eróticas regidas pelo princípio, denominado por seus adeptos, de SSC, ou seja, São, Seguro e Consensual. Esse princípio, central para o grupo, determina, portanto, como pré-requisitos à realização de jogos BDSM: a saúde física e mental dos envolvidos; o domínio das técnicas eróticas que serão aplicadas, a higiene dos apetrechos utilizados, o cuidado com o corpo do outro, portanto, a segurança; e a negociação entre os envolvidos sobre o que será feito e seus limites, consensualmente (Vera SILVA, 2016, p. 26).

Contudo, o senso comum e a Psiquiatria, ainda hoje, andam de mãos dadas ao considerar o amplo campo fetichista como patologias. Vera Silva (2016) realiza um estudo a respeito do interesse da medicina sobre as perversões sexuais, e como esta relação transparece nas cinco 
edições do DSM (em português, Manual Diagnóstico e Estatístico de

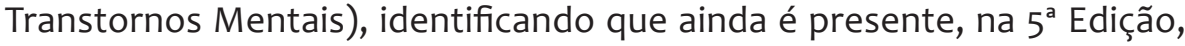
o paradigma genital da sexualidade, que torna perversas/anormais as sexualidades que não se dão a partir do gozo genital. A autora aponta que no período de revisão que antecedeu à publicação do DSM V, ainda que o grupo de trabalho responsável pela revisão dos transtornos parafílicos tenha emitido um relatório favorável à retirada dos diagnósticos de fetichismo e sadomasoquismo - a partir de fundamentadas pesquisas e trabalhos no campo - a edição final manteve a problemática inclusão do masoquismo, sadismo, transvestismo e fetichismo como transtornos parafílicos do mesmo grupo da pedofilia:

Os transtornos parafílicos inclusos neste Manual são: transtorno voyeurista (espiar outras pessoas em atividades privadas), transtorno exibicionista (expor os genitais), transtorno frotteurista (tocar ou esfregar-se em indivíduo que não consentiu), transtorno do masoquismo sexual (passar por humilhação, submissão ou sofrimento), transtorno do sadismo sexual (infligir humilhação, submissão ou sofrimento), transtorno pedofílico (foco sexual em crianças), transtorno fetichista (usar objetos inanimados ou ter um foco altamente específico em partes não genitais do corpo) e transtorno transvéstico (vestir roupas do sexo oposto visando excitação sexual) (AMERICAN PSYCHIATRIC ASSOCIATION, 2014, p. 685).

Ana Mota e Alexandra Oliveira (2014) também discutem os impactos dessa inclusão, salientando que a manutenção dessa categoria no DSM V apresenta riscos para as práticas de psicoterapia, que passam a ser desadequadas, desviando o foco das questões reais do/a cliente para a estigmatização e consequente mal-estar e isolamento social. As autoras, que entrevistaram BDSMistas, constataram a presença desse receio entre os/as participantes da pesquisa, que ao comentarem com profissionais da saúde suas experiências não-normativas, foram severamente reprimidos/as, e ainda participantes que mesmo fazendo uso regular de serviços de saúde mental, não possuem segurança em contar aos/às profissionais a respeito dessas experiências.

Regina Facchini (2008) identifica que as comunidades brasileiras de BDSM não enfrentam publicamente o conservadorismo como ocorre 
com o movimento LGBT, de maneira que não é contemplado na agenda política dos direitos sexuais. Esse distanciamento do espaço público e a preferência por estas vivências na esfera íntima não significam que não existam pautas ou elos entre as comunidades SM, mas sim que estas ligam-se principalmente em torno dessa necessidade de despatologização: "O principal elo entre elas parece ser a (des)identificação com o discurso psiquiátrico sobre perversões e parafilias e o desejo de criar alternativas de legitimação da prática do BDSM erótico" (Regina FACCHINI, 2008, p. 196).

Contudo, é importante ressaltar que a patologização das sexualidades desviantes têm um discurso conservador, fundado não apenas na medicina, mas também fortemente influenciado pela religião cristã ocidental. Ofir Grisales (2012) identifica que a religião têm se apropriado historicamente da definição dos corpos e da determinação do seus usos possíveis (o que é considerado puro), e a proibição dos desvios dessa determinação (o que seria considerado impuro). E é nesta tentativa de controle dos corpos e dos sexos, que Maria José Rosado-Nunes aponta como a Igreja compreende e se manifesta publicamente sobre a discussão dos direitos sexuais:

Para a Igreja, as questões relativas à sexualidade e à reprodução relevam da ordem da natureza, são questões que se situam fora do político, não sendo, portanto, objeto de "direitos". E quando busca interferir nas legislações nacionais nesses campos - uniões homossexuais, aborto, pesquisa com células embrionárias, eutanásia e outros - ela não o faz em nome do debate democrático que permite o confronto de opiniões diversas. Não há “opinião” nessas áreas. É em nome da competência que lhe foi outorgada por direito divino que ela dá sua palavra autorizada e intenta estendê-la a toda a sociedade, uma vez que é a própria natureza do que é humano o que está em jogo. Trata-se de questões que se situam para além do direito de intervenção dos seres humanos, que escapam à capacidade de decisão das pessoas, pois encontram resposta em uma ordem transcendente sobre a qual não se pode pretender qualquer controle (Maria José ROSADO-NUNES, 2008, p. 77).

É com base em dicotomias e/ou binarismos que o discurso religioso sobre a sexualidade se fundamenta, seja a dualidade puro/impuro, seja 
o discurso que determina características naturais - que correspondem à vontade divina, transcendental - e antinaturais, que contrariam os modelos naturais. Dentre estas, poderiam ser incluídas as mais variadas formas de diversidade sexual, desde orientações não-heteronormativas, outras expressões de gênero, e mesmo os diversos tipos de fetiche. E, nessas dicotomias, não cabem outras opiniões. Como bem ressaltou Maria José Rosado-Nunes, ao contrário, a busca por direitos de minorias sexuais ameaça a perpetuação desses discursos que passam a assumir posturas combativas. Aderindo muitas vezes aos discurso psiquiátrico, começa a formar-se uma sexologia religiosa (Marcelo NATIVIDADE; Leandro de OLIVEIRA, 2009) que delimita comportamentos sexuais saudáveis associados à aprovação divina, e patológicos associados à danação pecaminosa, o que inclui aí uma pluralidade de pecados.

Isso nos leva a considerar os recentes trabalhos baseados nas Teorias Queer e a problematização da situação das Dissidências Sexuais. Queer é um termo da língua inglesa comumente referido à "estranho, esquisito, singular, excêntrico" e muito usado para referir-se àqueles/as que não correspondem aos padrões heterossexuais de sexualidade e aos papéis de gênero esperados ao seu sexo biológico (André MUSSKOPF, 2005). O termo foi ressignificado por teóricos/as gays/lésbicas como uma reação ao seu uso pejorativo, e também para ampliar o até então assimilacionismo das categorias gays/lésbicas de forma a incluir outras possibilidades de sexualidades não-heterossexuais, dando visibilidade à fluidez, complexidade e multiplicidade da sexualidade humana (André MUSSKOPF, 2008). Nesse sentido, para o autor, a proposta central da Teoria Queer seria romper com os dualismos.

O trabalho de Guacira Louro endossa essa construção da Teoria Queer, tanto no campo do pós-estruturalismo quanto no seio dos movimentos de gays e lésbicas, como não apenas uma crítica à heteronormatividade compulsória, mas também à política de identidade do movimento homossexual dominante: "queer significa colocar-se contra a normalização - venha ela de onde vier" (Guacira LOURO, 2001, p. 546). Louro, assim como Musskopf, aponta a necessidade de uma mudança epistemológica que rompa com a lógica binária de uma forma efetiva, e também com os efeitos dessa lógica: a hierarquia, a classificação, a 
dominação e a exclusão (Guacira LOURO, 2001, p. 549). Paralelamente, Richard Miskolci aponta que esses processos identitários nos primórdios dos movimentos LGBT deram-se por busca de reconhecimento, mas que

Isto contrasta claramente com a proposta teórica queer de apontar as fraturas nos sujeitos, seu caráter efêmero e contextual, mas o papel do queer não é desqualificar os movimentos identitários, antes apontar as armadilhas do hegemônico em que se inserem e permitir alianças estratégicas entre os movimentos que apontem como objetivo comum a crítica e contestação dos regimes normalizadores que criam tanto as identidades quanto sua posição subordinada no social (Richard MISKOLCI, 2009, p. 152).

Caminhando entre várias áreas do conhecimento, a Teoria Queer encontrou também ressonância na Teologia, embora não sem suspeita, como bem afirma André Musskopf (2005), uma vez que a Teologia teve importante papel na normatização, conforme apontado. Porém, a partir do fortalecimento da Teologia da Libertação na década de 70, surgem vários movimentos libertários na Teologia, como a Teologia Feminista, Teologia Negra, e mais recentemente, a própria Teologia Queer, cujo objetivo seria desenvolver uma metodologia que buscasse contradir o heterocentrismo no contexto religioso (André MUSSKOPF, 2008).

Tendo como fundamento estas problematizações das Teorias Queer, que como bem ressalta Guacira Louro, "[...] permite pensar a ambiguidade, a multiplicidade e a fluidez das identidades sexuais e de gênero" (Guacira LOURO, 2001, p. 550), é possível pensar as experiências eróticas de sadomasoquismo e fetichismo como respostas às normatizações sexuais, sejam estas as proposições do que é uma sexualidade sadia ou normal - consideradas nos discursos médico/religiosos como primordialmente genital - bem como aos papéis de gênero atribuídos aos/às sujeitos BDSMistas/Fetichistas, e que no exercício de suas práticas desviantes, podem ser ressignificados ou subvertidos. Tal é o exemplo que pode ser encontrado nas relações FemDom dentro do campo do BDSM.

\section{UMA INTRODUÇÃO AO FEMDOM}

FemDom (Female Domination) é uma abreviação de origem inglesa que significa Dominação Feminina, indicando que dentro de deter- 
minada relação BDSM o papel do Top, também chamado de Dominante ou Dominador, é ocupado por uma mulher. O oposto é denominado MaleDom (Dominação Masculina). O gênero do bottom (ou submisso), nessas siglas é indiferente, isto é, uma relação FemDom pode ocorrer tanto com uma submissa quanto com um submisso, sendo a relação com este último o foco deste artigo. Outras nomenclaturas podem também ser usadas para descrever estes papéis, como Dona, Domme, Rainha ou Mistress, para a Top, ou escravo e até mesmo capacho para o bottom, havendo divergências internas dentro da comunidade sobre se essas nomenclaturas podem ser utilizadas como sinônimos ou se possuem significados independentes.

Além de nomear a posição feminina na relação, o termo FemDom é também revestido de conteúdos que denotam a ideia de supremacia feminina, conforme apontado por Marcelle Silva (2012), que define o FemDom como um conjunto de práticas que apregoam a supremacia feminina, isto é, que a mulher é superior ao homem a quem ela domina. Tal crença não necessariamente é adotada por seus participantes fora da play (cena), nas suas realidades baunilhas, mas indica que durante a encenação das práticas os/as sujeitos se guiarão a partir deste princípio.

Os encontros para as práticas de BDSM também recebem muitas nomenclaturas: jogos, play, encontros, mas o mais comum seria cena. Para Regina Facchini (2008), durante a cena BDSM os/as sujeitos adquirem personas, identidades comumente simbolizadas através dos apelidos e, embora seja performática e teatralizada, contendo uma liturgia/script que orienta a sua condução, não exclui a criatividade e o papel intenso das emoções que são suscitadas para os/as participantes:

Falar em "encenação" remete menos a um teatro ensaiado e totalmente previsível (que negaria tanto a criatividade e a habilidade em tocar pontos centrais da fantasia do parceiro de forma inusitada, qualidades tão valorizadas na arte dos Dominantes, quanto as intensidades emocionais que emergem da situação criada na cena), do que ao momento e ao espaço específico em que toda parafernália BDSM (instrumentos, elementos litúrgicos, existência de um ou mais "outros" que reconheçam o personagem vivido) são acionados para que a fantasia seja transposta para um campo muito específico da realidade: a cena (Regina FACCHINI, 2008, p. 191). 
Isso ressoa com o que diz Marcelle Silva (2012), de que a cena exige que os/as seus/suas personagens atenham-se ao script dos seus papéis, e no caso da Domme, que ela mantenha uma postura dominante e austera até o fim da cena. Apenas em caso de acionamento da palavra de segurança - que indicaria que um/a dos/as participantes não está sentindo-se seguro/a ou confortável em determinada prática, de acordo com as normas da play - a cena é interrompida, pois é esta a função da safeword.

Um insight particularmente completo e detalhado de uma cena BDSM do tipo FemDom pode ser encontrado no trabalho de Marcelle Silva e Antonio Paiva (2014), que descrevem não só a multiplicidade de práticas fetichistas possíveis como algumas nuances da dinâmica erótica entre a Domme e o submisso:

No Femdom, geralmente não acontece o sexo com penetração, ou seja, o homem submisso não usa seu órgão genital para penetrar a dominadora. $O$ submisso é alguém, tratado como um ser inferior às mulheres, às quais devem prestar reverências, ser disciplinado e entregar-se às vontades da figura feminina dominante: há uma passagem do corpo sujeito ao corpo objeto. Isso acontece quando a pessoa, no caso, o homem submisso, sente prazer com situações humilhantes, deseja ser inferiorizado, através de xingamentos e práticas de degradação, como "chuvas dourada, prateada e marrom", práticas de feminização, principalmente feminização forçada, a objetificação (uso do sujeito como uma cadeira ou móvel de decoração) e ainda jogos nos quais o submisso é tratado como um cachorro e/ou cavalo (chamados de petplay); também faz parte da humilhação erótica a possibilidade de vivenciá-la de forma privada ou exibição pública, online e off-line. O submisso pode ser masoquista, ou não. Masoquista é aquele que encontra prazer na dor, física e/ou psicológica, em jogos que variam de nível, pesado ou leve. A relação que pode se estabelecer na junção de um submisso e uma dominadora é geralmente chamada de $\mathrm{D} / \mathrm{s}$, necessariamente quando há o desejo de jogos de controle do outro, quando o submisso deseja ter seus movimentos e comportamento controlados (Marcelle SILVA; Antonio PAIVA, 2014, p. 5, grifos no original).

Como uma operação de erotização dos corpos (Maria GREGORI, 2015), a cena BDSM permite aos/às seus/suas participantes a vivência 
de suas fantasias e desejos fetichistas que são negociados previamente, isto é, os limites de intensidades, quais práticas podem compor a cena, quais liturgias serão seguidas, e em alguns casos, os valores (também chamados de tributos) que os submissos precisarão dispor para desfrutar a cena, caso seja realizada por uma Dominatrix Profissional (também chamada de Pro-Domme).

É o caso de Dommenique Luxor, autora do livro "Eu, Dommenique”. Na biografia contida no livro, publicado pela Editora Leya em 2012, consta que a autora é porto-alegrense, com passagem por faculdades de História, Direito e Economia. Tendo trabalhado em várias funções, dentre elas funcionária terceirizada da Petrobrás, haveria abandonado a vida convencional e se tornado Dominatrix em tempo integral. Muito aberta na mídia, a Dominatrix conta com Facebook', Instagram², canal

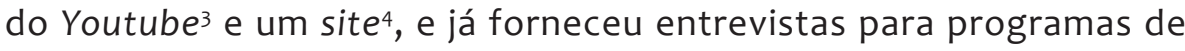
grande veiculação da Rede Bandeirantes como Agora é Tarde ${ }^{5}$ e A Liga ${ }^{6}$. Em suas redes sociais, relata suas experiências, divulga a cultura BDSM e anuncia serviços, em especial cursos/dicas/consultoria de empoderamento feminino e de dominação profissional.

O livro trata-se de um material autobiográfico, onde a Pro-Domme descreve algumas de suas sessões/cenas e as dinâmicas envolvidas com os submissos, bem como capítulos mais pessoais, em que relata alguns atendimentos e conversas com um psiquiatra. Alguns destes relatos serão discutidos a seguir.

\section{SUBVERSÕES E (PER)VERSÕES}

Nas primeiras páginas do livro, consta uma apresentação escrita pela própria Dominatrix, onde, de forma provocante, descreve-se fisicamente, seu estilo de dominação, suas práticas BDSM favoritas e suas

\footnotetext{
https://www.facebook.com/DominatrixDommenique/

https://www.instagram.com/mistressdommenique/

https://www.youtube.com/channel/UCTk7tpoLS7YmExaP8eEIU7A

http://www.cursodominatrix.com/

https://www.youtube.com/watch?v=-HDb3e8x01Q\&list=PLHMvx76gPo8IUJzwwwXikaqxfSGj IJ DL\&index $=2 \& \mathrm{t}=6 \mathrm{~s}$

6 https://www.youtube.com/watch?v=T7gzy_QoSAE\&list=PLHMvx76gPo8IUJzwwwXikaqxfSGj IJ_DL\&index $=2$ \&has_verified $=1$
} 
restrições dentro do campo. Constam também vários alertas para os candidatos interessados em marcar sessões sobre como se portar no ambiente e, também, qual o passo a passo para contatar Dommenique. Chama a atenção o estilo de linguagem, característico do FemDom:

Serás meu animal, meu capacho, meu serviçal e meu objeto. Meu corpo te envolverá numa viagem intensa e minhas ordens te conduzirão no caminho árduo da minha satisfação. Sou corajosa, independente, bonita e sedutora. Minha boca disciplina e humilha, meus pés recebem carinho e te chutam, meu desejo é intenso e profundo. Não te darei bônus sentimentais, mas a certeza de que nasceu para servir uma MULHER (Dommenique LUXOR, 2012, p. 5).

Nesta linguagem erótica inicial, introdutória, já é possível perceber a troca de poder tão característica do BDSM, consensual e prazerosa, que se materializa através da encenação de diversas práticas, algumas escandalizando pouco, outras muito, cujo efeito nas normatividades sexuais não pode ser outro além do confronto: contra o discurso médico de uma sexualidade normal/genital, contra o discurso religioso de uma sexualidade pura/permitida, contra o discurso de papeis socialmente delimitados para ambos os gêneros.

Ao falar sobre o masoquismo, muito se fala a respeito da dor, mas há que se considerar que a humilhação é um elemento muito recorrente, senão obrigatório, nas cenas BDSM. A humilhação pode ser verbal, variando em intensidade: desde alguns leves insultos à xingamentos degradantes; ou simbólica, presente em muitas práticas como o sissy maid (escravo doméstico) ou Scat (defecar no submisso, utilizando-o como uma privada). A humilhação é desejada e solicitada por alguns dos submissos que procuram a Pro-Domme, como é o caso do rapaz apresentado como Rafael, que convence Dommenique, ainda iniciante, a estabelecer uma relação 24/7 (uma relação BDSM em período integral, sem diferenciação entre a cena e a realidade baunilha) com ele durante um mês:

Sim, Senhora! É isso mesmo que eu imploro que faça. Me use, me molde, me trate como um lixo, um cachorro, um mordomo, como quiser! Me bata, me tire sangue. Sou o escravo da Rainha e à Rainha devo servir. Não tenho vontade própria (Dommenique LUXOR, 2012, p. 49). 
A predominância da humilhação diante do sofrimento físico surge também para Maria Gregori, que identificou que não se trata do prazer com a dor em si, mas da contextualização do "espancamento em meio a um jogo erótico que envolve recompensas e castigos, de modo a envolver a dor em outros elementos da fantasia" (Maria GREGORI, 2015, p. 260). Esta humilhação teatralizada e erotizada aparece na narrativa das sessões de Dommenique intrinsecamente ligada à uma contestação dos papéis de gênero. O próprio FemDom em si já estabelece rupturas com o machismo estrutural ao permitir que o homem exerça na cena uma posição subalterna e à mulher uma posição de comando, poderio. Nas palavras de Marcelle Silva e Antonio Paiva: “A experimentação se dá pelo fato de as pessoas estarem 'reinventando as representações culturais para delas, obterem um novo prazer', mais próximos da criatividade do que da normatividade" (Marcelle SILVA; Antonio PAIVA, 2014, p. 10).

Os mesmos autores relatam ainda que a humilhação, neste contexto, tem como objetivo uma quebra e ruptura da resistência psicológica deste homem submisso, que ao longo da vida teria aprendido que o poder lhe seria inerente por possuir um símbolo de poder que é o pênis. Desta maneira, a dinâmica estabelecida na cena através de práticas como a própria humilhação em si, feminização e inversão, de acordo com Marcelle Silva e Antonio Paiva (2014), realizam um desmonte e uma despersonalização neste homem de toda a construção cultural de gênero que ele aprendeu e usa para se ver como um homem. Para Regina Facchini estas práticas se definem como:

Inversão de papéis é um jogo de Dominação/submissão (D/s) no qual a Domme assume a postura de um macho dominante, o que pode envolver a prática de penetração do escravo. A feminização é um jogo que pode ou não estar associado à inversão, no qual um escravo ou submisso é feminizado com o uso de roupas, lingerie, maquiagem e sapatos femininos (Regina FACCHINI, 2008, p. 183).

Há, no trabalho dos autores Marcelle Silva e Antonio Paiva, a sensação de um caráter libertador assumido pelos submissos que realizam essas práticas, o que abre a discussão para o espaço sadomasoquista como um lócus não apenas transgressor dos papéis de gênero mas tam- 
bém de experimentação de novas identidades de gênero (Marcelle SILVA; Antonio PAIVA, 2014). Nesse sentido podemos trazer à luz o conceito de performance de gênero, de Judith Butler, que torna-se vívido ao discutir papeis de gênero dentro da cena BDSM. Para a autora "A performatividade não é, assim, um «ato» singular, pois ela é sempre uma reiteração de uma norma ou conjunto de normas" (Judith BUTLER, 2000, p. 121). Ainda, gênero é a performance que representa e reitera as normas de sexualidade estabelecidas. É possível perceber, na narrativa, novas significações para estas performances, como o escravo apelidado de Alice:

Que tesão esse homem safado! Veio aos poucos, me conquistando, abrindo a guarda e agora está aqui na minha casa, andando de quatro toda semana. Nos primeiros dias, eu mandava que lambesse e massageasse meus pés e me servisse oralmente depois de lavar minhas calcinhas sujas e limpar todos os meus sapatos - com a língua enorme. Alguns encontros depois, não andava a não ser de quatro na minha presença, rebolando aquela bunda carnuda pra lá e pra cá. Logo já usava uniforme de empregada e uma calcinha minúscula enterrada (Dommenique LUXOR, 2012, p. 34).

Marcelle Silva (2012) havia identificado em seu trabalho que o casal entrevistado praticava feminização por iniciativa do próprio homem, e Dommenique Luxor (2012) possui clientes/escravos que a procuram com este intuito, a exemplo de Alice, já citado, e Daniel, a quem a Dominadora penetra com o dedo e com um eletroestimulador no Capítulo 8. Retornando aos autores Marcelle Silva e Antonio Paiva que, ao discutirem as práticas de inversão e feminização, identificam que a troca de papéis de gênero ocorrida na cena possui forte elemento de humilhação, mas salientam que os sujeitos da pesquisa buscam justamente essas práticas humilhantes para realizar fantasias sexuais:

De acordo com o material etnográfico, alguns homens fantasiam serem possuídos sexualmente por uma mulher, através da inversão e/ou crossdresser, outros desejam ver-se ou imaginar-se forçados a serem travestidos de mulher, submetidos e humilhados, encontrando na feminização forçada a fantasia ideal para satisfazer seu desejo (Marcelle SILVA; Antonio PAIVA, 2014, p. 5). 
Neste tipo de prática, é comum que homens feminizados sejam forçados a realizarem atividades domésticas como lavar banheiros, cozinhar, lavar louça, entre outros. Forçados em destaque, porque muitos deles, incluindo o cliente de Dommenique chamado de Alice, pagam por sessões com a expectativa de exercerem este papel. Curioso perceber que, enquanto no senso comum brasileiro, a fantasia sexual da empregada persiste forte e desnuda diversas assimetrias sociais e, até mesmo, erotiza violências de gênero, neste contexto, estes homens desejam se tornar a empregada, mas sem a expectativa de uma relação sexual. Nas cenas BDSM de Sissy Maids, estes homens de fato investem horas no processo de faxina doméstica na casa de suas Dominadoras, recebendo apenas insultos, espancamentos e outras práticas de humilhação. Em nossa realidade, o espaço doméstico é socialmente considerado como um espaço feminino, o que o tornaria desvalorizado na lógica machista. Mas no BDSM encontramos homens que desejam e anseiam por performarem este lugar oposto:

Essa espécie de "degradação", baseada na domesticidade e presente nas encenações, inverte a equação que se para a esfera masculina do mercado e a esfera feminina do lar, sendo o cliente, homem, aquele quem paga para realizar as tarefas "sujas" do lar, trabalho normalmente não pago e executado pelas mulheres, empregadas ou esposas (Maria GREGORI, 2008, p. 592).

A inversão, que pode ou não estar associada à feminização, surge como uma outra oposição à uma lógica normativa das relações heterossexuais: aqui, no ato sexual, o homem passa a ser receptivo à mulher. Sabemos o quanto o prazer anal é um tabu para os homens heterossexuais, mas a cena BDSM cria espaços de experimentação de novas formas de prazer também para os corpos masculinos. Enquanto na sociedade baunilha, a associação com o feminino costuma ser ofensiva para homens heterossexuais, seja na postura receptiva no sexo, seja na ocupação do espaço doméstico, no contexto sadomasoquista os mesmos homens performam esta associação e descobrem prazer nela.

Não só a performance de gênero torna-se mais fluida como a própria expressão da orientação sexual encontra novas possibilidades 
dentro do campo BDSM, conforme indicado por Regina Facchini (2008). A autora identificou que suas entrevistadas, mulheres praticantes, abriam-se à experiências com outras mulheres, seja como dominadoras ou como escravas, mesmo que algumas se identificassem como heterossexuais em sua vida baunilha. Isso pode ocorrer, em partes, por uma característica que Marcella Althaus-Reid (2000) aponta como própria do Fetiche: uma ambiguidade que transita perpetuamente entre o natural e o artificial, animado e inanimado, sem fixar-se em nenhum polo, sendo ambos ao mesmo tempo e nenhum. Para ela, há uma dualidade indecisa inerente à categoria, que aproxima a categoria do Fetiche da práxis Queer, por em sua própria essência, ser não-binária. Esta ambiguidade, ou fluidez de fronteiras, é percebida também por Maria Gregori, que ressalta uma flexibilidade presente nas comunidades BDSM - visível nas relações não-diádicas e não-genitais, e a possibilidade de relações $\mathrm{D} / \mathrm{s}$ que independam da orientação sexual. Nas palavras da própria autora:

Seguindo tal perspectiva, o SM comercial, o lesbianismo SM e as manifestações SM entre gays masculinos constituem alternativas que, no limite, problematizam os modelos que supõem naturalidade e normalidade entre as fronteiras que delimitam homens e mulheres e, mais particularmente, o comportamento sexual masculino como sendo ativo e o feminino como sendo passivo, além de esfumaçarem os limites que separam o prazer da dor, o comando e a submissão (Maria GREGORI, 2015, p. 262).

Estas cenas BDSM desestabilizam não apenas as performances de gênero como a própria Teologia. Tida por Marcella Althaus-Reid como a arte de apagar contradições (Marcella ALTHAUS-REID, 2000, p. 45), a Teologia Sistemática prezou desde sempre pela homogeneização, e quando um homem e uma mulher invertem suas performances de gênero de uma forma consensual, regular, e sentem prazer nisso, há uma ameaça ao próprio sistema da heterossexualidade religiosa, que padroniza e regulamenta experiências sexuais entre homens e mulheres.

As relações FemDom ameaçam também o discurso médico, que historicamente se encarregou de delimitar os limites da sexualidade, encerrando uma variada gama de expressões em um constructo chamado 
de perversão. De acordo com Vera Silva (2016), por um certo período, a medicina considerou que a reprodução deveria ser o grande fim da sexualidade e nisto, apenas uma pequena dose de prazer era permitida. Posteriormente, o prazer por si só passou a ser menos perverso, contudo, continua estritamente ligado à ideia do gozo genital. Fora da genitalidade, as diversas formas de prazer ainda fomentam a ideia de perversão, como é o caso da fetichização de objetos, de ações e de partes do corpo consideradas não-erógenas.

Porém no FemDom, como já apontado por Marcelle Silva e Antonio Paiva (2014), a penetração masculina é bastante incomum. O encontro sexual se dá a partir de práticas e encenações que deslocam essa primazia da genitalidade, e que quando exercida, é de forma invertida da lógica tradicional feminino/receptivo e masculino/ativo. Para Fátima Freitas (2010), todo o corpo é erotizado e utilizado no BDSM, em sua totalidade, e não apenas os órgãos genitais são considerados erógenos. Percebe-se um confronto direto, nessas cenas, com todo o constructo médico que delimita o que é ou não perverso, o que é ou não o prazer.

Há que se considerar, também, o choque que o masoquismo masculino provocou (e provoca) neste discurso, por permitir aos homens uma outra performance de gênero que não a do dominador biologicamente natural, na cena. Ainda recorrendo à Vera Silva, encontramos em seu trabalho que a psiquiatria já considerou homens masoquistas como "parcialmente afeminados" (Vera SILVA, 2016, p. 28), de forma que estes casos se tornaram clinicamente mais importantes e chamativos à época do que o sadismo masculino (que reiterava a masculinidade viril). Percebe-se, a partir daí, que o pensamento médico se preocupava mais em tratar dos homens que não queriam dominar mulheres, e sim serem dominados por elas, em clara insubmissão às normas tradicionais de gênero. Este ponto chama especial atenção, pois, considerando que Maria Gregori (2015) aponta que os submissos na comunidade BDSM existem em maior número do que os dominadores, pode-se inferir que não são poucos os homens heterossexuais em busca de vivências eróticas emasculinizantes.

A partir das experiências sexuais dissidentes, Marcella Althaus-Reid (2000) ressignifica a perversão como um sinônimo de outra interpre- 
tação, muito mais conectada à realidade, isto é: per-versão (perverter/ questionar a versão). No BDSM, conforme é possível observar nos relatos de Luxor, a violência e a hierarquia são pervertidas de forma erótica, retirando-se o teor de controle social e normatividade, ressignificando-o para o gozo pessoal. Anne McClintock (1994 apud Maria GREGORI, 2015) indica que o SM performa o poder social com suas assimetrias que, quando teatralizadas, estão sujeitas a mudanças e novas inflexões. Este jogo de poder, esta troca erótica, permite pensar em ressignificações em várias esferas, especialmente na categoria Gênero.

\section{CONTRADIÇÕES E LIMITAÇÕES}

É preciso considerar, contudo, que alguns/algumas autores/as apontam problemáticas que questionam se essa ruptura consegue superar totalmente as performances de gênero tradicionais. Não podemos deixar de notar que, ao lidar com o atravessamento de tantos tipos de relações de poder, este universo parece também transitar na ambiguidade de ora erotizar relações de poder de forma subversiva, ora, através do mesmo erotismo, reafirmá-las.

Marcelle Silva e Antonio Paiva (2014) denunciam que persiste um modelo de heterossexualidade compulsória que, muitas vezes, simplesmente inverte homem/mulher e que é explicitado nos xingamentos mulherzinha, puta, vadia, utilizadas pelas próprias Dominadoras, e que podem perpetuar ideias de desvalorização feminina mesmo em um contexto de supremacia feminina. As autoras vão além e tensionam o fato de que o homem é tomado como mulher, neste contexto, e a mulher assume características tradicionalmente tidas como masculinas como a virilidade e a agressividade. Um exemplo dessa situação pode ser encontrado no livro:

"Você é muito vadiazinha né? Tá dando a bundinha por aí?

"Não, minha Deusa... Sou toda sua, sou apertadinha, a Senhora sabe."

“Abre a calça para mim, cadela. Quero ver” (Dommenique LUXOR, 2012, p. 33).

Apesar de Regina Fachini (2008) apontar que é evidente a presença de uma desnaturalização das relações de poder nas relações BDSM, 
cabe o questionamento de que isso pode não ser tão evidente em todas as relações e em todas as cenas, pois sem a devida crítica por parte dos seus praticantes, existe a possibilidade de perpetuação de alguns estereótipos sociais. Se, de acordo com Fátima Freitas (2010), os conceitos de masculinidade e feminilidade são constantemente negociados dentro das cenas e relações BDSM, pode-se inferir que o resultado de tal negociação depende do quão interessados/as ou dispostos/as estão os/as envolvidos/as em ressignificarem os conceitos. O quão longe dos papéis tradicionais de gênero querem os/as praticantes se distanciar? A resposta lança luz à outra pergunta: o quão envolvidos/as estão os/ as mesmos/as com essa discussão de gênero?

Há também que se considerar que, pelo seu caráter privado, afastado do espaço público, a subversão realizada dentro da cena BDSM apresenta ainda pouco impacto na realidade baunilha, que ao guiar-se pelas convenções de gênero tradicionais e hegemônicas, não consegue admitir a saída das vivências sadomasoquistas das quatro paredes em que ocorrem. Isso se torna presente nos relatos que Dommenique faz ao seu psiquiatra, quando desabafa não conseguir estabelecer um relacionamento baunilha pois os homens, embora inicialmente apoiassem seu trabalho, com o tempo passavam a sentir ciúmes e ter "vontade de me ter só pra ele, uma safada encoleirada. Mas eu sou um corpo-objeto-carne a serviço de mim mesma. Não rolaria nunca" (Dommenique LUXOR, 2012, p. 159). A Dominadora ainda relata como valoriza sua liberdade sexual, possui consciência do seu corpo e do seu prazer, não apenas dentro do seu trabalho, mas também fora dele. A resposta do psiquiatra só reforça a preocupação masculina em domesticar essa liberdade:

Domme, acho que para você só um corno. Você é muito direta. Tem que ser um cara que aceite isso, o jeito que você é, meio safadona, sem noia. Você já sabe do que gosta e deixa claro. Mas naquelas né... achar um cara que seja corno mesmo é difícil (Dommenique LUXOR, 2012, p. 155).

A masculinidade hegemônica pode até considerar o poderio sexual feminino em uma cena, mas quando esta mulher ousa exercer essa mesma liberdade sexual na realidade baunilha, tradicional, é convidada 
a se conformar com as ideologias do lado de cá, como foi o caso do psiquiatra, ou exercer essa liberdade com um homem só, a safada encoleirada como no caso dos homens com quem Dommenique se relacionara. O discurso religioso muito contribui para essa dificuldade em valorizar a liberdade sexual feminina. De acordo com Marcella Althaus Reid (2000), o ideário construído a respeito de Maria, Mãe de Jesus, reflete uma forte domesticação e decência do feminino na América Latina que não permite outras formas de expressão. Este é um dos modelos para o ser feminino que ainda hoje domestica a expressão e vivência de tantas mulheres, até mesmo Dommenique, incitada à uma conformação de que não conseguiria manter um relacionamento amoroso paralelo ao seu trabalho.

Embora o aspecto teatral seja um dos principais recursos na luta contra a patologização, exatamente por dissociar a realidade baunilha da realidade BDSM, quando considerado dentro da discussão de gênero, percebe-se que esta mesma vivência de duplicidade pode entravar uma desconstrução mais profunda. Se na relação FemDom homens e mulheres performam seus gêneros de forma subversiva, não há necessariamente uma garantia de que aplicam essas ressignificações em suas vidas públicas. Embora Dommenique e outras mulheres identifiquem terem encontrado mais autoconfiança e empoderamento a partir do FemDom em suas vidas cotidianas, será que os homens submissos se posicionam a favor dos direitos das mulheres, neste mesmo espaço cotidiano?

Outras críticas envolvem questões de classe presentes no cenário fetichista. Ao estudar a emergência do SM no mercado erótico, Maria Gregori (2015) tece inquietações com a associação entre o fetichismo e o neoliberalismo. Glauco Ferreira (2011), Regina Facchini (2008) e Marcelle Silva (2012) já haviam também apontando um caráter elitista do BDSM, devido aos custos envolvidos no material das cenas e da hegemonia de uma classe média/alta presente em seus estudos. No relato de Luxor, um homem operário comparece em uma sessão e, em seus pedidos, escancara diferenças de raça e classe entre ele a Dominadora, deixando-a desconfortável e reflexiva por muito tempo: "Porque eu preciso servir uma mulher assim, tão bonita e tão branca? Às vezes eu fico revoltado, 
pois me sinto humilhado, degradado. Não sou burro. Mas minha vontade não passa" (Dommenique LUXOR, 2012, p. 171).

Pensar nesse aspecto é também abrir o questionamento de como a comunidade BDSM pode se comportar de forma restrita e seletiva. Regina Fachini (2008), ao observar em campo clubes de encontro na temática, percebeu que embora houvesse certo espaço de destaque para pessoas que fogem aos padrões estéticos e geracionais, ainda assim a presença dessas pessoas, e também da população negra, era bastante reduzida em comparação à população branca e à modelos estéticos mais hegemônicos. Mesmo que as posições de dominação ou submissão, em tese, dependam apenas dos desejos e da identificação dos/as sujeitos, acessar e realizar os mesmos dentro da comunidade BDSM demanda um forte elemento financeiro, seja nos points de encontro físico, seja através das sessões tributadas (alternativa para muitos submissos uma vez que os espaços de encontro tendem a se concentrar nas grandes capitais) e no mercado erótico virtual das FinDommes, que cobram por seus conteúdos. Dispor de capital para viajar, comprar acessórios, pagar por conteúdos e sessões é uma realidade muito restrita em um país com tantas desigualdades sociais, o que nos leva a pensar como e se - os/as sujeitos que não dispõem desses recursos vivenciam suas experiências sadomasoquistas.

O BDSM possui, certamente, um caráter contestatório e transgressor dos papéis tradicionais de gênero e dos paradigmas de sexualidade, e abre brechas para uma ressignificação e vivência mais libertária dos mesmos, sendo este o ponto principal deste trabalho. Mas não poderia deixar de pontuar também suas limitações, uma vez que surgem ainda como entraves à uma plena e completa (per)versão dos papéis de gênero. Há uma forte prevenção aos riscos físicos/psicológicos presente na base SSC, mas creio que ainda seja necessário ampliar as discussões dentro da comunidade sobre os riscos de reproduzir e perpetuar assimetrias sociais de gênero, classe, etnia, entre outros.

\section{FIM DA CENA}

A partir da crescente visibilidade da comunidade BDSM, objetivou-se dar sequência à uma discussão a respeito do potencial dessas 
práticas em subverter e ressignificar papéis tradicionais de gênero e de sexualidade que ainda são alimentados por discursos normativos médicos e religiosos. Partindo dos relatos do livro "Eu, Dommenique", foi possível elencar três práticas BDSMistas (Humilhação, Inversão e Feminização) que, performativamente, desconstroem esses discursos, mostrando que o fetiche possui potencial para escapar ou confundir a lógica do binarismo (Marcella ALTHAUS-REID, 2000), em certos contextos.

Embora esta discussão valorize esse caráter transgressor, foi preciso apontar algumas limitações presentes na comunidade em romper plenamente alguns elementos assimétricos não apenas em relação à gênero, mas também em outras problemáticas sociais. Ao apontar tais limites, espera-se fomentar novas discussões que agreguem e fortaleçam a comunidade na direção da superação dos mesmos, pois, mesmo com essas contradições, limitações e problemáticas, o espaço fetichista reserva uma rica fonte de reflexões a respeito da heterossexualidade e sua consequente performática de gênero da maneira como foi estabelecida no discurso heteronormativo-genital, que carecem de futuros trabalhos que se aprofundem no tema.

O BDSM, paradoxalmente, utiliza-se da violência em suas práticas, ao mesmo tempo em que impõe-se uma ética rigorosa a fim de proteger seus praticantes de violências não consentidas. A base São, Seguro, Consensual, delimita estas práticas indicando que nem tudo é permitido, mas apenas aquilo que se encontra no campo de desejo de participantes adultos/as, em plena consciência de suas decisões e resguardados dos possíveis riscos, e, acima de tudo, que tenham consentido e negociado previamente as hierarquias, práticas e doutrinas. O que nos leva ao questionamento: o que seriam das hierarquias próprias da Psiquiatria e do Cristianismo se ousassem questionar e negociar seus limites e práticas com aqueles a quem dominam?

Os questionamentos, portanto, longe de se esgotarem, continuam suscitando novas perguntas e revelando as limitações do presente artigo. Só de início, é possível se perguntar: os praticantes de BDSM mantém alguma vinculação religiosa ou refletem sobre intersecções entre questões espirituais e sexuais? E no contexto próprio da saúde mental, como ampliar a discussão surgida em Ana Mota e Alexandra 
Oliveira (2014) a respeito da resistência dos/as participantes em revelar suas vivências fetichistas em contextos de terapias, devido ao receio da patologização?

Há que se considerar também a necessidade de um aprofundamento maior em outros formatos e dinâmicas de relações BDSM, que não couberam nesta discussão, especialmente discutir as relações de gênero presentes na dominação tipo MaleDom. É possível encontrar formas de subversão dos papéis de gênero tradicionais, quando a cena BDSM parece reproduzir os mesmos? E como se dá a performática de gênero em relações BDSMistas vivenciadas por casais LGBTQI+? Acreditamos que também seja relevante considerar as diferentes nuances das relações FemDom pagas (ou tributadas) para as relações BDSM que são estabelecidas fora deste contexto, sem o elemento financeiro.

Para finalizar, André Musskopf diz que o que "sexo, gênero e sexualidade têm em comum entre si, assim como com todas as outras características que definem a identidade dos seres humanos, é que elas são significadas apenas em nossos corpos" (André MUSSKOPF, 2005, p. 188). O corpo é, certamente, o principal papel onde Dommenique Luxor escreve seus relatos - no seu próprio e nos de seus submissos. As histórias inscritas narram dor, prazer, perversão, teologia, medicina, gênero e sexo, mas principalmente, resistência. Uma vez que, para Marcella Althaus-Reid (2000) a heterossexualidade encontra-se amarrada à genitalidade, garantindo privilégios àqueles/as que se submetem à seus dogmas, mas em última instância, fazendo com que os opressores sejam engolidos pela própria opressão, em um tipo de armário asfixiante (Marcella ALTHAUS-REID, 2000, p. 33), é necessário olhar para outras experiências de sexualidade que ousam sair destes armários.

Pois esta resistência autoriza sujeitos/as a performarem personagens que representam a si mesmos/as, desafiam modelos rígidos e decentes e que a resistência que os permite sair do armário - seja um armário fetichista, homossexual, lésbico, bissexual, transgênero, travesti e até mesmo um armário heterossexual ideal (Marcella ALTHAUS-REID, 2000) - também os permite viver uma liberdade fora das normativas sociais, e por consequência, (per)vertê-las. 


\section{REFERÊNCIAS}

ALTHAUS-REID, M. Indecent Theology. London, Routlegde, 2000.

AMERICAN PSYCHIATRIC ASSOCIATION. Manual diagnóstico e estatístico de transtornos mentais: DSM-5. 5 ed. Porto Alegre: Artmed, 2014

BUTLER, Judith. Corpos que pesam: sobre os limites discursivos do sexo. In: LOURO, Guacira Lopes. O corpo educado - Pedagogias da sexualidade. Belo Horizonte: Autêntica, 2000. FACCHINI, Regina. ENTRE UMAS E OUTRAS: Mulheres, (homo)sexualidades e diferenças na cidade de São Paulo. 323 f. Tese (Doutorado em Ciências Sociais) - Instituto de Filosofia e Ciências Humanas, Universidade Estadual de Campinas, Campinas, 2008.

FACCHINI, Regina; MACHADO, Sarah Rossetti. DO SADOMASOQUISMO ERÓTICO AO BDSM: discursos de legitimação, direitos sexuais e convenções sociais sobre gênero e sexualidade no contexto brasileiro pós-redemocratização. In: Seminário Internacional Fazendo Gênero 10, 10., 2013, Florianópolis. Anais... Florianópolis: UFSC, 2013. p. 1-12.

FERREIRA, Glauco Batista. Produção de sujeitos, sexualidades e mercadorias no BDSM: as técnicas e os circuitos SM em San Francisco na etnografia de Margot Weiss. Estudos Feministas, v. 22, n.1, p. 361-391, jan-abr. 2014

FREITAS, Fátima Regina Almeida. Bondage, dominação/submissão e sadomasoquismo: uma Etnografia sobre práticas eróticas que envolvem prazer e poder em contextos consensuais. In: Seminário Internacional Fazendo Gênero 9, 9., 2010, Florianópolis. Anais... Florianópolis: UFSC, 2010. p. 1-7.

GREGORI, Maria Filomena. Limites da sexualidade: violência, gênero e erotismo. Revista de Antropologia, v. 51, n. 2, 2008.

GREGORI, Maria Filomena. Prazeres perigosos: o contrato e a erotização de corpos em cenários sadomasoquistas. Etnográfica, v. 19, n. 2, p. 247-265, 2015.

GRISALES, Ofir Maryuri Mora. Corpo e sexualidade no cotidiano das mulheres protestantes de Cali-Colômbia. Mandrágora, v.18. n. 18, p. 27-52. 2012.

SILVA, Marcelle Jacinto da. Linguagens, experiências e convenções de gênero e sexualidade no BDSM. 107 f. Trabalho de Conclusão de Curso (Bacharel em Ciências Sociais) - Departamento de Ciências Sociais, Universidade Federal do Ceará, Fortaleza, 2012.

SILVA, Marcelle Jacinto da; PAIVA, Antonio Crístian Saraiva. Pensando corpo, gênero e sexualidade em contexto sado-fetichista. Ponto Urbe, n. 15, 2014.

SILVA, Vera Lucia Marques da. A Psiquiatrização do sexo não normativo: BDSM e a $5^{\text {a }}$ revisão do Manual Diagnóstico e Estatístico de doenças mentais. Vivência, n. 48, p. 25-38, 2016.

LOURO, Guacira Lopes. Teoria Queer - uma política pós-identitária para a educação. Estudos Feministas, v. 9, n. 2, p. 542-553, 2001.

LUXOR, Dommenique. Eu, Dommenique. Rio de Janeiro: Leya, 2012 
MISKOLCI, Richard. A Teoria Queer e a Sociologia: o desafio de uma analítica da normalização. Sociologias, v. 11, n. 21, p. 150-182, jan-jun. 2009.

MOTA, Ana Mafalda; OLIVEIRA, Alexandra. Repensar o BDSM para além da dor: Sadomasoquismo e direitos sexuais. Revista Iberoamericana de Salud y Ciudadanía, v. 3, n. 1 e 2, p. 82-104, 2014.

MUSSKOPF, André Sidnei. Quando sexo, gênero e sexualidade se encontram: reflexões sobre as pesquisas de gênero e sua relação com a Teoria Queer a partir da teologia. História Unisinos, v. 9, n. 3, p. 184-189, set-dez. 2005.

MUSSKOPF, André Sidnei. Viadagens teológicas: itinerários para uma teologia queer no Brasil. 525 f. Tese (Doutorado em Teologia) - Instituto Ecumênico de Pós-Graduação em Teologia, Escola Superior de Teologia, São Leopoldo, 2008.

NATIVIDADE, Marcelo; de OLIVEIRA, Leandro. Sexualidades ameaçadoras: religião e homofobia(s) em discursos evangélicos conservadores. Sexualidad, Salud y Sociedad - Revista Latinoamericana, n. 2, p. 121-161, 2009.

ROSADO-NUNES, Maria José. Direitos, cidadania das mulheres e religião. Tempo Social, v. 20, n. 2, nov. 2008.

Submetido em: 7-11-2019

Aceito em: 20-5-2020 